\title{
A review of cyberbullying legislation in Qatar: Considerations for policy makers and educators
}

\author{
Mairéad Foody ${ }^{\mathrm{a}}$, Muthanna Samara ${ }^{\mathrm{a}, *}$, Aiman El Asam ${ }^{\mathrm{a}}$, Hisham Morsi ${ }^{\mathrm{b}}$, Azhar Khattab ${ }^{\mathrm{b}}$ \\ a Department of Psychology, Kingston University London, Penrhyn Road, Kingston upon Thames, KT1 2EE, UK \\ ${ }^{\mathrm{b}}$ Hamad Medical Corporation (HMC), P.O. Box 3050, Doha, Qatar
}

\section{A R T I C L E I N F O}

\section{Article history:}

Received 5 June 2016

Received in revised form 20 September 2016

Accepted 19 October 2016

Available online 10 November 2016

\section{Keywords:}

Bullying

Cyberbullying

Victimization

Legislation

School policy

Children

\begin{abstract}
A B S T R A C T
Cyberbullying is a worldwide problem affecting mental health, education, safety and general well-being for individuals across the globe. Despite the widespread availability of the Internet, research into prevalence rates of cyberbullying in Qatar is lacking and legislating for the crime has been slow to develop. Recently there have been some positive initiatives in the country such as a Cybercrime Prevention Law, the development of a National ICT Strategy, and a website detailing safe practice guidelines for Internet usage. However, the implementation and usage of these initiatives are still limited and there is a lack of awareness of cyberbullying in Qatar. As a result, the risk factors and consequences among school-aged children are unknown. The current paper presents an evaluation of the legislative and public policy solutions to cyberbullying available in Qatar, and outlines the critical challenges that could potentially face educators in shaping best practice guidelines for the future.
\end{abstract}

(c) 2016 Elsevier Ltd. All rights reserved.

\section{Contents}

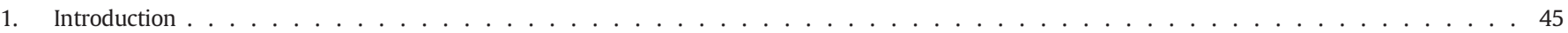

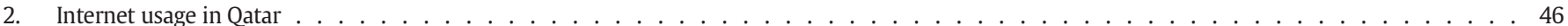

2.1. Traditional bullying and cyberbullying in Qatar . . . . . . . . . . . . . . . . . . . . . . . . . . . . . . . . 46

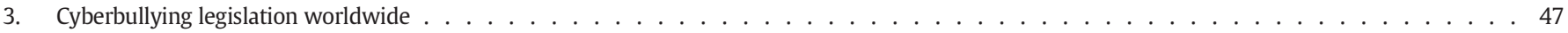

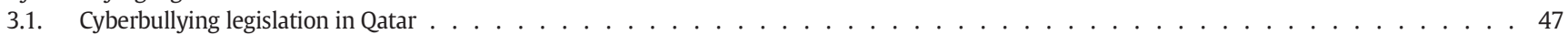

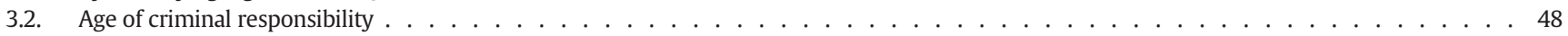

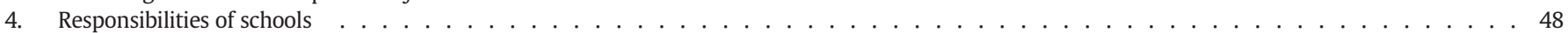

5. Challenges and difficulties . . . . . . . . . . . . . . . . . . . . . . . . . . . . . . . 49

5.1. The future of cyberbullying in Qatar . . . . . . . . . . . . . . . . . . . . . . . . . . . . . . . . . 49

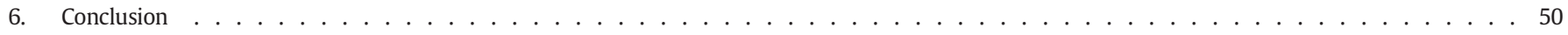

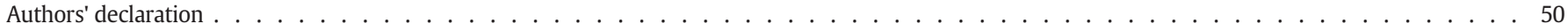

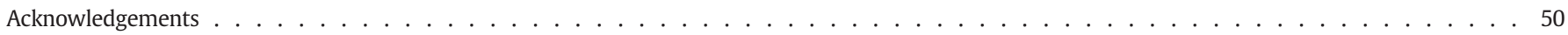

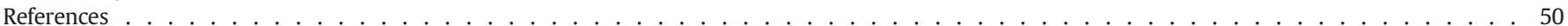

\section{Introduction}

Bullying is a common behavior among children, adolescents and adults, which can be witnessed in all countries across the world. In addition to its well-known international prevalence, the impact of traditional bullying (face to face bullying) is believed to have a range of negative outcomes for victims, including health and psychological

\footnotetext{
* Corresponding author.

E-mail address: M.Samara@Kingston.ac.uk (M. Samara).
}

problems (e.g., Wolke \& Samara, 2004; Wolke, Schreier, Zanarini, \& Winsper, 2012). Bullying involves repeated physical and/or mental harassment as a consequence of an imbalance in power between the bully and the victim (Olweus, 1993). It can take the form of direct behaviors such as physical assault and verbal abuse (Monks et al., 2009); or relational behaviors such as manipulation of peer relationships to cause harm to the victim (e.g., gossiping and/or spreading rumors; Wolke, Woods, Bloomfield, \& Karstadt, 2000). In recent times, the widespread availability of the Internet has exacerbated these problem behaviors such that a new form of peer harassment has emerged called 
cyberbullying. However, despite increased recognition of this phenomenon worldwide, appropriate legislation in Qatar is lacking. This paper details the current state of legislation for cyberbullying in Qatar and argues that research is needed to investigate current policies and to develop new laws that promote child safety by setting an official standard of prevention.

Cyberbullying is defined by Smith et al. (2008a) as "an aggressive, intentional act, using electronic forms of contact such as social networking sites, repeatedly and over time against victims who cannot easily defend themselves" (p. 376). Similar to traditional bullying there are several negative behaviors that constitute cyberbullying such as: harassment, humiliation, exclusion, cyber stalking, flaming (i.e. writing abusive comments online), defamation, denigration, impersonation, outing and exclusion (Feinberg \& Robey, 2009; Newey \& Magson, 2010; Pearce, Cross, Monks, Waters, \& Falconer, 2011). However, there are also numerous factors that distinguish the two. For example, the power imbalance in cyberbullying experiences may refer to: anonymity (Butler, Kift, \& Campbell, 2009); the bully's technological skills (Grigg, 2010); and/or the ability to invade their victims' privacy (Aricak et al., 2008; Beran \& Li, 2005; Kift, Campbell, \& Butler, 2010). Repeated harassment results from the continual viewing of the bullying incident online by different people over a short period of time (Campbell, Cross, Spears, \& Slee, 2010). Furthermore, cyber bullies do not receive direct feedback for their actions, which can result in a lack of empathy and understanding of the consequences for the victim (Feinberg \& Robey, 2009).

Recent studies investigating this phenomenon have conclusively shown that its impact on victims leads to a range of negative experiences including the development of psychological problems (Cénat et al., 2014; Chang et al., 2013). Specifically, research has shown that cyberbullying can cause brief and long-term periods of psychological distress for both victims and bullies (Reijntjes, Kamphuis, Prinzie, \& Telch, 2010) and in extreme situations can even lead to suicide (Tokunaga, 2010). As a result, the risk factors associated with cyberbullying are quickly becoming recognized by educational researchers and policy makers worldwide as they look to emerging legislation for prevention and appropriate consequences (Nansel et al., 2001; Smith et al., 2012).

\section{Internet usage in Qatar}

Qatar is a small Arab country with a population of only 2,003,700 (Statistics Authority, 2014). Despite its size, it has made extensive economic progress in the last decade, resulting in affluence for a large portion of society. The population has changed drastically in recent years because of the influx of foreign workers employed to accomplish Qatar's development plans (Qatar Population Status, 2012). As a result there is an imbalance in residents where the majority of the working population are expatriates (96\% compared to $4 \%$ nationals in 2011 ; Qatar Population Status, 2012). The changing economic and social climate in the country has presented a challenge to Qatari natives as they encounter expatriate values different to their own traditional norms. However, the government is striving to create a contemporary approach to such issues and have a clear future agenda on the world stage in areas such as sports, healthcare and education (Qatar National Development Strategy, 2011-2016).

Together with the growth of the economy, Internet usage has grown considerably for the current generation in Qatar. According to Internet World Stats (2010) Internet and broadband penetration is similar to the European average and among the highest in the Middle East ( $51.8 \%$ vs. $31.9 \%$ for the Middle Eastern average). Furthermore, it was reported in Qatar's ICT Landscape (2009) that the country has a high uptake of mobile phones ( $97.8 \%$ of households), which is nearly $10 \%$ higher than the EU average. Despite the widespread availability of the Internet, legislating for cybercrimes and particularly for cyberbullying has been slow to develop.

\subsection{Traditional bullying and cyberbullying in Qatar}

Like many countries worldwide, bullying is a significant social problem in Qatar, particularly for school-aged children. The Global School-based Student Health Survey (GSHS, 2011) in Qatari schools found that $48 \%$ of boys and $35 \%$ of girls aged $13-15$ years were bullied on one or more occasion in the previous month. In addition, an annual report by the Supreme Education Council (SEC, 2011/2012) ${ }^{1}$ found that $14 \%$ of students disagreed with the statement "my school is a safe place to be" ( $12 \%$ of which were primary students and $15 \%$ were secondary). However, these studies are limited in that most definitions of traditional bullying make reference to the behaviors being repetitive instead of isolated incidences (Smith et al., 2008a, 2008b). The GSHS required participants to comment on bullying experiences that occurred once or more in the previous month. This does not provide a comprehensive analysis of the situation, as it did not focus on the repetitive nature of bullying. Indeed, establishing a worldwide consensus on the definition of traditional bullying is a widely debated topic and the conclusions drawn from studies are not always comparable due to varying concepts and measurement (Kazarian \& Anmar, 2013; Kowalski, Giumetti, Schroeder, \& Lattanner, 2014; Scheithauer, Smith, \& Samara, 2016).

Studies investigating parents' perspectives on traditional bullying in schools have produced contradictory results. For example, the SEC (2011/2012) report found that $90 \%$ of primary parents and $91 \%$ of secondary parents felt that their child "gets along well with other students". However, when parents were interviewed for the Annual Omnibus Survey of life in Qatar (SERSI, 2012), less than half of all interviewees (44\%) said their child did not bully other children while $36 \%$ said their child sometimes did. Twenty percent of parents said this was certainly true of their child. Cultural differences and discrepancies in parents' views of what constitutes bullying might explain these contradictory results. While awareness of bullying and the associated negative consequences is commonplace in western societies, it is relatively non existent in the Arab world. This could be due to the lack of an Arabic term to describe such behaviors (Kazarian \& Anmar, 2013) and/or a lack of awareness at a community level. In the Arabic speaking countries and specifically in Qatar, there is no common Arabic term used to explain the concept of bullying (Samara, Sherif, Perkins, Morsi, \& El Asam, 2014), although new alternatives to the term such as 'peer harassment' are becoming more prevalent. Indeed this may be a consequence of having a relatively new education system (e.g., the SEC in Qatar was only established in 2002). Consequently, government led research into relevant and associated factors such as child well-being and mental health is limited.

Only two published studies have investigated prevalence rates of cyberbullying in Qatar. Microsoft (2012) commissioned a study investigating online bullying among 8-17 year olds compared to the rest of the world. This study defined cyberbullying as "the willful and repeated harm inflicted through the use of computers, cell phones, and other electronic devices" (Hinduja \& Patchin, 2015, p. 11). The results demonstrated that Qatar had the 19th highest rate of cyberbullying out of 25 countries worldwide and rates of cyberbullying were above average in Qatari students (32\% compared to 24\%). Furthermore, Qatari youths were slightly below the worldwide average in terms of knowledge about the topic (50\% compared to $57 \%$ ). The study also highlighted interesting comparisons between online and offline bullying in Qatari youths. For example, $28 \%$ of students reported experiences of being an online victim compared to $68 \%$ offline and $32 \%$ reported cyberbullying compared to $44 \%$ for traditional bullying. However, this study did not provide information regarding the psychological impact on victims and there was no differentiation between different forms of traditional

\footnotetext{
${ }^{1}$ Now named Ministry of Education and Higher Education
} 
bullying. This could suggest a misdefinition of bullying in Qatar where it is predominately considered to be an act of physical violence (Samara et al., 2014). Nevertheless, the figures are high and an indication of the difficulties facing Qatari youths in present times. One possible reason could be that parents are unaware of the issue and are not providing preventative steps at home (e.g., limited or supervised time online) (Lereya, Samara \& Wolke, 2013). Indeed, the Microsoft study found that Qatari parents were less likely than the worldwide average in taking protective steps against cyberbullying. Additionally, although antibullying programs can help to tackle this problem (Samara \& Smith, 2008) Qatari schools lack such interventions.

Another study by Onsor, Alameer, Almonabih, Alqahtani, and Tweem (2012) found that 19.5\% of Qatari youths were bullies, 36\% were victims, $18.6 \%$ were bully/victims and $25.9 \%$ were neutrals. The authors found that local children were more likely to be bullies ( $21.1 \%$ vs. $17.4 \%$ ) and non-nationals were more likely to be victims of bullying (39.9\% vs. 33.1\%). The most prevalent types of bullying were insulting (bullies: 20.4\%; victims: 22.9\%), ignoring (bullies: 19.2\%; victims: $11.3 \%$ ) and making fun (bullies: $17.8 \%$; victims: $15.1 \%$ ). The study was limited in that investigations of cyberbullying were limited to mobile phone usage (bullies: $4.9 \%$; victims: $4.4 \%$ ) without taking into account other means of Internet and social networking.

Although the reviewed studies in Qatar provide a platform for investigating cyber- and traditional bullying, they also highlight the lack of available research and bullying related information in the context of Qatar. These are the only empirical studies investigating prevalence rates of cyberbullying and none of them make reference to the psychological impact for Qatari youths or the coping strategies they utilize to deal with such experiences. This makes it difficult to compare such experiences to other countries and/or to suggest appropriate interventions that may have been implemented internationally. For example, the KiVa program in Finland suggests an online computer program that incorporates education and psychological intervention (e.g., dealing with negative thoughts) for dealing with cyberbullying incidents (Williford et al., 2013). Nevertheless, the research in Qatar and indeed, other Gulf states is not at the point where online or offline interventions are being investigated. The research is currently in its infancy where governments are still trying to investigate prevalence rates. As such, there is a strong need for extensive research into these experiences for bullies, victims and bully/victims in Qatar. In particular, conclusions need to be drawn as to what exactly the term cyberbullying means for young people in the country. Only then can we begin to implement awareness campaigns about the associated dangers and behavior change programs, which are designed to help the victims in need.

\section{Cyberbullying legislation worldwide}

In contrast to Qatar, cyberbullying legislation in western countries is more extensive. In 2011, forty-six U.S. states had specific bullying laws in which all but one outlined directives to school districts to adopt anti-bullying policies. Furthermore, in the same year, thirty-six states included provisions in their education codes for cyberbullying (U.S. Department of Education, 2011). The laws vary drastically in the US and some states have more advanced legislation than others. For example, states such as New York, Hawaii and Michigan have proposed that cyberbullying should be considered a criminal offense worthy of severe punishment such as imprisonment. While in other states, schools are considered responsible (for a review see Hinduja \& Patchin, 2014).

Like many countries worldwide, high profile cases of cyberbullying in the U.S. media have led to widespread legal transformations. For example, Seth's Law (2011) in California was named after a 13-year-old Californian boy who took his own life because of years of harassment as a result of his sexual orientation, which his school failed to deal with appropriately. This law requires schools to adopt an anti-bullying policy and specific investigation processes for dealing with similar crimes (AB 9 "Seth's Law", 2011). Furthermore, the state of California extended their definition of bullying to account for harassment through electronic means in the AB 756 (2011) bill that outlines a punishment of suspension or expulsion for cyber bullies.

In the UK there are currently ten legal Acts that can be considered relevant for bullying and cyberbullying; however their full applicability is challenging (El Asam \& Samara, 2016). Relevant to the education system, there are the School Standards and Framework Act (1998, Section 61), which makes a commitment to "preventing all forms of bullying among pupils" and the Education and Inspections Act (2006) that emphasizes the school's responsibility to ensure their students' online safety by holding them accountable for the regulation of pupils' conduct outside of the school day (Section 90). However, cyberbullying is not considered to only be a school-based problem. At present, children above the age of 10 can face charges for such incidents, which can happen inside or outside of an educational setting. The age of criminal responsibility ( 10 years old) is seen as a major challenge facing new cyberbullying legislation in the UK (e.g., El Asam \& Samara, 2016). In addition, all schools in England are legally required to have an antibullying policy as indicated by the Department for Education (DfE) s' regulations (Smith et al., 2008b).

In the Gulf, most countries have Cybercrime Laws that focus on penalizing general computer crimes related to state security, fraud, economy and public interest. However, these have also made some provision for cyberbullying. For example, the Anti-Cybercrime Law (2007) in Saudi Arabia outlines a punishment of imprisonment or a cash fine for invasion of privacy and/or defamation by information technology devices (Article 3 ). Although this appears a positive step, Saudi Arabia has been criticized for utilizing this law in an alternative manner to limit freedom of speech in the country. In particular, the 2014 annual report by the Gulf Centre of Human Rights stated that the Anti-Cybercrime Law was being used to penalize and imprison human rights defenders who were utilizing websites and blogs to spread information about human rights violations in the country.

Other gulf states have similar approaches, which appear to focus on general computer crimes and have limited relevance to bullying activities. In the United Arab Emirates (UAE) the Federal Decree-Law no. (5) of 2012 on Combating Cybercrimes generally targets crimes against the state such as disobeying public laws using electronic means (Article 31). However, Article 21 sets a punishment of imprisonment for at least 6 months and a cash fine for invading another's privacy using electronic means. The Cyber Crime Law of Oman (2011) contains one relevant article (16), which makes it illegal to use Information Technology (e.g., camera phones) to spread photos or news in the form of slander and defamation about an individual or family. The penalty is imprisonment for a period of 1-3 years and a fine between 10000MR (approx. $\$ 2600)$ and 50000MR $(\$ 13,000)$. Although, there are some, albeit limited, provisions for cyberbullying in these laws, in general, they do not include clear guidelines regarding consequences of school bullying among children and adolescents.

\subsection{Cyberbullying legislation in Qatar}

Before 2014, Qatar regulated for cyberbullying within its penal laws (Qatari Penal Code, 2004) without a clear section or specific chapter dedicated to the crime. For example, Chapter 5 of Part 3 of the Penal Code contains a section on "Computer Crimes" which outlines various punishments for cybercrimes such as hacking, (Article 371), the spreading of viruses (Article 378) and credit card fraud (Article 382). In addition, Chapter 5 of Part 7 on "Immoral and Disgraceful Actions" states that anyone who uses wire, wireless or electronic means to disturb or inconvenience another person is liable for up to six months imprisonment and/or a fine of up to 3000 riyals (approx. \$800; Article 293). However, some of these Articles consider harassment in different forms, for example, through hacking or disturbing others using an 
electronic device. These Articles target crimes committed with computers as opposed to crimes committed online regardless of the device used.

Other sections of the Penal Code are related to defamation and bullying in general, but not cyberbullying specifically. Article 326 stipulates up to two years imprisonment or 20,000QR (approx. $\$ 5500$ ) for "accusing somebody of committing a legally punishable crime, or harms dignity or honor thereof or exposes him to public disdain or malice". Furthermore, Article 327 states "whoever defames a public employee because of their job or occupation, or if the offence damages the reputation of the family" will be punished with imprisonment for a term not exceeding three years and/or a maximum fine of $20,000 \mathrm{QR}$. Invasion of privacy is also a criminal offense that the Penal Code directs up to a one-year prison sentence and fine of 5000QR (approx. \$1300; Article 331). This could include bullying activity such as racially motivated threats, hurtful emails or chat-room postings.

In Qatar, the changes in technology have naturally triggered challenges that the traditional Penal Code may not be developed enough to deal with. As a result the country's National Information and Communication Technology (ICT, 2015) plan set an agenda for research, policy, awareness and legislation of all ICT related issues in Qatar. A new Cybercrime Prevention Law has recently been enacted. The Cybercrime Prevention Law no. 14 of 2014 specifically targets cybercrimes by including crimes against humans such as attacks on another person's identity, or any action considered a technically unlawful act (e.g., using a computer to commit credit card fraud). However, similar to the Penal Code, the Cybercrime Prevention Law does not specifically define the term cyberbullying, although it does make some provisions for the offense. For example, it outlines a maximum fine of QR100,000 (approx. \$27,500) for any person who uses the Internet or an IT device/technique to violate social values; to disseminate information in a manner that disrespects another person's privacy; and/or to engage in slander. While the publication of this new law is a progressive step forward for Qatar, it is not enough to combat the complex crime of cyberbullying. In particular, the distinguishing factors of cyberbullying such as repetitive behavior and/or an imbalance of power are not explicitly targeted and as such, a definition of cyberbullying needs to be included to ensure adequate sanctions.

In addition to the new Cybercrime Prevention Law, Qatar has attempted to implement a visible approach to online safety and ICT in general and awareness of cyberbullying is being promoted through ongoing cyber safety initiatives in the country. The Supreme Council of Information and Communication Technology (ictQatar) is responsible for the country's planning and implementation of ICT initiatives and online safeguarding of children. In 2012, ictQatar launched the National Committee for Internet Safety (NCIS) in an effort to establish various initiatives to promote the safe and responsible use of the Internet by everyone, especially primary and secondary school students. One recent ictQatar campaign highlighted privacy issues and advocated for responsibility of personal online safety. This was aimed at parents, educators and children to encourage them to rethink their Internet habits. More specifically, ictQatar's current campaign is aimed at raising awareness of cyberbullying and an official site (safesapce.qa) was launched in 2010 that contains policies, best practices and resources for cyber safety. However, there have been no investigations about the extent to which these suggestions have been implemented in schools and thus the influence on rates of cyberbullying is unknown. Although these initiatives are a good start, they need to be audited and researched extensively to show their use and impact on the society as a whole and on schools and children specifically. This will help to identify problem areas in the awareness process and provide information for creating appropriate policies and legislation. In addition, such investigations will give a local framework to work from, as opposed to using international research as a guide to inform interventions.

\subsection{Age of criminal responsibility}

The age of responsibility documented by Qatar's Penal Code is seven years old. The Juveniles Act No. 1 of 1994 defines a juvenile as a person over seven and under the age of 16 at the time of the alleged crime. Juveniles who commit crimes under the age of 14 are subject to the measures outlined in the Juvenile Act, which can range from warnings (Article 9) to a vocational training placement (Article 11) depending on the severity of the crime. Those aged from 14 to 16 years receive reduced penalties compared to older individuals under the Penal Code. Children aged 16 years and older are normally tried in the legal system as adults. This touches on the controversial and sensitive issue of criminalizing children. Often, children or adolescents may not appreciate the potential harm and seriousness of their actions and a prosecution is unlikely to be in the public interest. Thus, if the legislation provided by the state does not prevent cyberbullying, then it should not be used as a primary solution (Campbell \& Završnik, 2013; Gillespie, 2006). However, education and awareness are sometimes not enough to act as deterrents (Campbell et al., 2010).

One study by Paul, Smith, and Blumberg (2012) found that British secondary school students believed that they were best placed to safeguard themselves from cyberbullying in terms of stopping or preventing an incident from happening. However, a lack of understanding and education at their age, limits their protection of themselves and each other. Therefore a multilevel approach including collaboration from a range of services such as: policy makers (e.g., Education and Health Councils), educators (e.g., schools, teachers, counselors, psychologists), solicitors and legal practitioners/services (e.g., judges, courts), in conjunction with children and adolescents and their parents is necessary when developing strategies for dealing with cyberbullying (Paul et al., 2012). In reality, a wide range of preventive measures need to be implemented (Campbell et al., 2010; King, 2010) and researchers are currently trying to find a way to mitigate for this (see Lidsky \& Garcia, 2012).

\section{Responsibilities of schools}

Some researchers have argued that schools should take an active role in preventing both offline and online bullying. For example, several court cases in the U.S. have demonstrated that schools are obligated to take action when presented with evidence of cyberbullying among their students (Hinduja \& Patchin, 2011). In terms of accountability, the literature often discusses the legal responsibilities of schools as opposed to the criminal accountability of the children (Shariff \& Hoff, 2007). In England, schools are responsible for regulating student behavior off school premises (Education \& Inspections Act, 2006) and schools are permitted to implement consequences for cyberbullying occurring outside of school grounds but affecting life in school (Paul et al., 2012). For example, teachers are permitted to confiscate any tools leading to bullying (e.g., smartphones). In addition, it is a legal requirement for schools to have an anti-bullying policy and there is a consensus among educators and researchers that schools should also be legally required to have a cyberbullying policy or at least to provide for it within existing policies (Diamanduros, Downs, \& Jenkins, 2008; Smith et al., 2012). This conveys the school's dedication to the prevention of all types of bullying (Pearce et al., 2011; Samara \& Smith, 2008; Smith et al., 2012) and provides a comprehensive procedure to follow if an incident of cyberbullying is reported (Kift et al., 2010; Smith et al., 2012). However, schools in the UK are slow to create such policies and Smith et al. (2012) found that cyberbullying was inadequately mentioned in school policies within the UK with only a $23 \%$ increase from 2002 to 2008.

The proportion of schools with anti-bullying or anti-cyberbullying policies is undocumented in Qatar and there is no set procedure for schools within the current legislation for dealing with cyber bullies or victims. At present, there is a behavioral policy designed by the SEC for all public schools in Qatar to adhere to, which includes brief 
definitions of different behaviors including bullying and cyberbullying and also a list of preventative measures and sanctions (Supreme Education Council, 2013). However, it does not include the roles of the parents and their children in the implementation of this policy and the follow-up measures. Also, there is no research available which has investigated this policy and the impact of its existence on offline or online bullying and/or victimization rates in Qatar.

Schools in Qatar face a bigger challenge than many western countries such as the U.S., which have highly evolved legal systems and public access to court records. Gathering information on cyberbullying cases in Qatari courts is a challenge despite their importance in informing school policies and appropriate legal provisions. While looking at international cases (e.g., Seth's Law, 211) and similar cases to help inform Qatari legislation, public access to local court cases would provide a more informed and up to date approach to dealing with cyberbullying (Hinduja \& Patchin, 2011).

Schools in Qatar should have a comprehensive procedure to follow when cyberbullying is reported. Similar to successful interventions in other countries worldwide (e.g., Olweus, 1994) whole-school approaches should be implemented in Qatari schools to tackle cyberbullying behavior. This approach should include targeting different levels and domains in the school community including staff and students by building a supportive school culture, implementing appropriate policies and improving the skills of staff and students on how to deal with such experiences (Samara \& Smith, 2008). In addition, forming partnerships between school members, families and the wider community is crucial (COST IS0801, 2013). For this to happen, clear guidelines of the schools' responsibilities in Qatar should be designed and implemented including the responsibility for students' behaviors inside or outside the school. In addition, schools should be legally required to have a cyberbullying policy that outlines the responsibility of all concerned parties with a clear procedure to follow if an incident of cyberbullying is reported. Furthermore, these should be recorded and monitored with documentation of the procedures and outcomes clearly evident and accessible by external authorities (e.g., SEC).

Finally, we are also in need for online psychological treatment for victims and bullies as a means of coping with the distress caused from cyberbullying experiences. More access to individual psychological therapies and not just school or education-based programmes should be considered a crucial step forward in cyberbullying research (Foody, Samara, \& Carlbring, 2015).

\section{Challenges and difficulties}

The current legal situation appears to vary from country to country when accounting for these incidences. However, even though some countries (e.g., the UK) have well-constructed legislations and laws (legal Acts) that could cover for cyberbullying related offenses, there are associated difficulties that can hinder their effectiveness (see review by El Asam \& Samara, 2016). For prosecution the message must convey a 'credible' threat and must be within the public interest (Agate \& Ledward, 2013). Without this "a case ... must not proceed, no matter how serious or sensitive it may be" (Crown Prosecution Service, 2012). Thus, there is no consideration for the psychological impact on the victim despite it being deemed necessary to consider these risks when assessing whether a legal solution is appropriate (Butler et al., 2009; Vandebosch, Beirens, D'Haese, Wegge, \& Pabian, 2012). Nevertheless, if the victim wishes to pursue legal action they must have sufficient funds and be prepared for the case to reach an even wider audience, including the media (Agate \& Ledward, 2013). This may have an additional negative impact on the individual's health and well-being. Thus, there should be further research on how effective the proposed cyberbullying law is and how often it will be used and implemented in Qatar.

One vital aspect that needs to be considered in every country is that of criminalizing children. Very often, children and adolescents may not appreciate the potential harm and seriousness of their communications and a prosecution is rarely likely to be in the public interest. Thus, if the law does not prevent cyberbullying it should not be used as a primary solution (Campbell \& Završnik, 2013; King, 2010). However, education can lack the ability to act as a deterrent and the consensus among researchers is that a wide range of preventive measures need to be implemented (Campbell et al., 2010; Kift et al., 2010; King, 2010). Thus it is important to take into account that there are international challenges that are sometimes related to particular websites. For example, social networking sites do not take legal action in the case of cyberbullying because the costs are too high (Davies \& Lee, 2008). Instead they offer information about changing their privacy settings, blocking and reporting the bully (Vandebosch et al., 2012). It is therefore necessary for Qatar to have its own laws with regards to the use of these sites, but importantly these will have to be implemented in a manner that does not affect free speech.

\subsection{The future of cyberbullying in Qatar}

In most countries worldwide bullying and cyberbullying are widely believed to be unacceptable behavior at both a community and broader societal level. As a result, education strategies in the media designed to create awareness about safeguarding children are common (e.g., Safer Internet Day in the UK). However, it has been argued that these traditional approaches are not enough (Slovak \& Singer, 2011) and victims often believe that the best approach is avoidance (Juvonen \& Gross, 2008) and very often choose to suffer in silence (Samara \& Smith, 2008; Smith \& Samara, 2003). Indeed, the literature suggests that victims of traditional - and cyber-bullying are unlikely to discuss their experience with an adult (Campbell et al., 2010; Ybarra \& Mitchell, 2004). Furthermore, victims perceived adults to be technologically incompetent (Diamanduros et al., 2008) and thus, unable to offer help or support. There are currently no studies which have investigated Qatari youths' coping strategies for cyberbullying experiences and whether or not they are more likely to deal with it alone or to confide in an adult. However, like many current social issues in Qatar, looking to international research provides a platform to open a dialog on the topic. As such it is imperative that Qatar model countries like the UK and that local communities educate their children about cyberbullying and how social interactions differ online compared to face-to-face (COST IS0801, 2013). However, the responsibility of the community is only slowly evolving in Qatar through initiatives like those implemented by ictQatar. Making bullying and cyberbullying a socially unacceptable behavior is still a necessary task and in practice, most of the responsibility and liability for dealing with such incidences falls to schools and legislators.

Qatar's vision for the country's youth over the next decade is outlined in its National Development Strategy 2011-2016. Consequently, research into cyberbullying and effective legislation are essential elements in Qatar's national plan for the future. However, research into traditional bullying in Qatari schools is still lacking and Qatar is unique in that there is more information available to its citizens on cyberbullying than traditional bullying. It could be argued that research on this phenomenon has skipped a step in Qatar because it has not naturally evolved from traditional bullying research, despite some studies demonstrating that the latter is more prevalent than the former (Microsoft, 2012). A look to other countries and strategies applied worldwide is essential if Qatar is to have efficient legislation in place for dealing with cyberbullying in the long term. Furthermore, cyberbullying legislation in Qatar will need to lend itself to the global stage as cyberspace has no borders and victimization is not contained within the school grounds or bound to cultural norms (Shariff \& Hoff, 2007). Attempts to generalize and subsequently implement a universal method of dealing with cyberbullying are difficult as countries worldwide adopt different terminology, moral viewpoints, and legal systems (Paul et al., 2012). 
Although important, the legal method for tackling cyberbullying is not the only method of creating change and prevention. Several researchers have highlighted the fact that providing laws and policies is only one element to a web of actions that need to be undertaken such as educational programs and technology solutions (Snakenborg, Van Acker, \& Gable, 2011). A basic step in bullying prevention initiatives is to understand the nature of the society in which the problem is being tackled. As such, the community holds the most important aspect to be engaged and studied if changes in the prevalence of cyberbullying and associated risk factors are to be targeted. In fact, bullying legislation in western countries is often pursued under pressure from a community event. For example, several laws in the US were enacted after incidences of shootings in public schools (e.g., Columbine high school in Colorado), after which it was revealed that the shooter had previously been the victim of peer harassment (see Hinduja \& Patchin, 2009).

Parental supervision is also an important aspect to combating cyberbullying (Vandebosch et al., 2012), however, research suggest that the majority of children and adolescents explore cyberspace without adequate supervision (Benzmiller, 2013). Therefore, there needs to be an interaction between the parents and schools when applying interventions (Kift et al., 2010; Pearce et al., 2011). It is vital for adults to be technologically confident and understand the importance of IT for social interactions (Diamanduros et al., 2008). Research has revealed that positive parental involvement and support is associated with fewer bullying incidents among children, while poor supervision and lack of attention could cause the child to be victimized (Lereya et al., 2013). Furthermore, there should be more initiatives from policy educational makers and educators to increase the involvement of parents in Qatar in the design and implementation of cyberbullying laws and preventative measures in schools.

In general, there is a need for contemporary and research-led cyberbullying legislation in Qatar that provides clarity in terms of educators' responsibility and protection of children. It is imperative that research is undertaken to examine the coherence and adaptability of the existing provisions in the country. A clear research agenda is necessary to critically evaluate and contextualize the legislative and public policy solutions available to Qatar and to inform policy makers of how to tackle this problem. Ultimately, there is a need to investigate what is currently happening in Qatar for educators who do not have appropriate and official guidance. This research output will also act as an aid to the drafting of specific legislation in the future.

\section{Conclusion}

Little socio-legal research has been conducted to establish the legal parameters of cyberbullying, or the scope for legislative intervention to protect against victimization in Qatar. At present, the country has legislated for cyberbullying by including it within "pockets" of relevant law in other legal areas. Even with the introduction of the new Cybercrime Prevention Law, cyberbullying with regards to children and adolescents specifically is not clearly targeted. Furthermore, the efforts of educational institutions for an effective anti-bullying policy has been similarly ad hoc and will continue to be until a clear legal requirement is established. Thus, prevention as well as punitive measures for these behaviors needs to be clearly laid out. This review provided a broad analysis of the difficulties facing Qatar for legislating for cyberbullying. However, it is important to note that these issues are worldwide concerns. Indeed, some countries are more conscious of the impact of this social problem on their citizens when compared to Qatar, yet there are few examples of the 'perfect' cyberbullying legislation worldwide. Looking to countries like the US and the UK will provide framework for what Qatar should consider as next steps, but national research to investigate cultural-specific aspects of cyberbullying is just as important to develop appropriate legislation.

\section{Authors' declaration}

The authors declare that there are no competing financial interests exist. The paper has not been published elsewhere and it has not been submitted simultaneously for publication elsewhere.

\section{Acknowledgements}

This work was supported by the Qatar National Research Fund (QNRF) a member of Qatar Foundation, Doha, Qatar, National Priority Research Programs (NPRP) under Grant (NPRP 5-1134-3-240) funded to Dr. Muthanna Samara. The authors would like to thank QNRF for their support and the teachers and head teachers in Qatar who provided us with information and advice.

\section{References}

California Assembly Bill. (AB) 9: Seth's Law. Chapter 723. (2011). [online]. California. Available from: http://www.leginfo.ca.gov/pub/1112/bill/asm/ab_00010050/ab_9_ bill_20111009_chaptered.html ([Accessed: 29/07/2014])

Agate, J., \& Ledward, J. (2013). Social media: How the net is closing in on cyber bullies. Entertainment Law Review, 24(8), 263-268.

Aricak, T., Siyahhan, S., Uzunhasanoglu, A., Saribeyoglu, S., Ciplak, S., Yilmaz, N., \& Memmedov, C. (2008). Cyberbullying among Turkish adolescents. Cyberpsychology E' Behavior, 11, 253-261.

Benzmiller, H. (2013). The cyber-Samaritans: Exploring criminal liability for the "innocent" bystanders of cyberbullying. Northwestern University Law Review, 107(2) 927-962.

Beran, T., \& Li, Q. (2005). Cyber-harassment: A study of new method for an old behavior Journal of Educational Computing Research, 32, 265-277.

Butler, D., Kift, S., \& Campbell, M. (2009). Cyber bullying in schools and the law: Is there an effective means of addressing the power imbalance. eLaw Journal, 16, 84-114.

Campbell, M. A., \& Završnik, A. (2013). Should cyberbullying be criminalized? In P. K. Smith, \& G. Steffgen (Eds.), Cyberbullying through the new media: Findings from an international network (pp. 65-82). East Sussex: Psychology Press.

Campbell, M. A., Cross, D., Spears, B., \& Slee, P. (2010). Cyberbullying: Legal implications for schools (Vol. 118). The Centre for Strategic Education.

Cénat, J. M., Hébert, M., Blais, M., Lavoie, F., Guerrier, M., \& Derivois, D. (2014). Cyberbullying, psychological distress and self-esteem among youth in Quebec schools. Journal of Affective Disorders, 169(0), 7-9. http://dx.doi.org/10.1016/j.jad. 2014.07.019.

Chang, F. -C., Lee, C. -M., Chiu, C. -H., Hsi, W. -Y., Huang, T. -F., \& Pan, Y. -C. (2013). Relationships among cyberbullying, school bullying, and mental health in Taiwanese adolescents. Journal of School Health, 83(6), 454-462. http://dx.doi.org/ 10.1111/josh.12050.

COST IS0801 (2013). Guidelines for preventing cyber-bullying in the school environment: A review and recommendations. Available from: http://sites.google.com/site/ costis0801/

Crown Prosecution Service (2012). Interim guidelines on prosecution cases involving communications sent via social media. London: The Crown Prosecution Service.

Davies, M. R., \& Lee, B. A. (2008). The legal implications of student use of social networking sites in the UK and US: Current concerns and lessons for the future. Education and the Law, 20(3), 259-288.

Diamanduros, T., Downs, E., \& Jenkins, S. J. (2008). The role of school psychologists in the assessment, prevention, and intervention of cyberbullying. Psychology in the Schools 45(8), 693-704.

El Asam, A., \& Samara, M. (2016). Cyberbullying and the law: A review of psychological and legal challenges. Computers in Human Behaviour, 65, 127-141.

Executive Summary Report Social \& Economic Survey Research Institute (SERSI) (2012h). Annual Omnibus Survey: A survey of life in Qatar. Available from: http://sesri.qu.edu. qa/sites/default/files/Eng/ExecutiveReports/2012/OmniBus2012.pdf

Feinberg, T., \& Robey, N. (2009). Cyberbullying. Education Digest, 74(7), 26-31.

Foody, M., Samara, M., \& Carlbring, P. (2015). A review of cyberbullying and suggestions for online psychological therapy. Internet Interventions, 2(3), 235-242.

Gillespie, A. A. (2006). Cyber-bullying and harassment of teenagers: The legal response. Journal of Social Welfare E' Family Law, 28, 123-136.

Global School-based Student Health Survey for Qatar (2011). Available from: http:// www.emro.who.int/images/stories/hed/documents/GSHS/Qatar_GSHS_FS_2011.pdf

Grigg, D. W. (2010). Cyber-aggression: Definition and concept of cyberbullying. Australian Journal of Guidance and Counselling, 20(2), 143-156.

Hinduja, S., \& Patchin, J. W. (2009). Cyberbullying fact sheet: A brief review of relevant legal and policy issues. Cyberbullying Research Center (Available from: http://www. cyberbullying.us/cyberbullying_legal_issues.pdf. [Accessed 05/05/2014]).

Hinduja, S., \& Patchin, J. W. (2011). Cyberbullying: a review of the legal issues facing educators. Preventing School Failure, 55(2), 71-87.

Hinduja, S., \& Patchin, J. W. (2014). State cyberbullying laws: A brief review of state cyberbullying laws and policies. Cyberbullying Research Center (Available from: http://www.cyberbullying.us/Bullying_and_Cyberbullying_Laws.pdf. [Accessed 13/ 042014]).

Hinduja, S., \& Patchin, J. W. (2015). Bullying beyond the schoolyard: Preventing and responding to cyberbullying (2nd edition ). Thousand Oaks, CA: Sage Publications. 
Qatar Juveniles Act No. 1 of. (1994). [Online]. Available from: http://www.almeezan.qa/ LawPage.aspx?id=26\&language $=$ en

Kingdom of Saudi Arabia. Anti-cybercrime law. (2007). [online]. Kingdom of Saudi Arabia. Available from: http://www.citc.gov.sa/English/RulesandSystems/ CITCSyste/Documents/LA_004_\%20E_\%20Anti-Cyber\%20Crime\%20Law.pdf ([Accessed: 03/04/2014])

Qatar penal code. (2004). [Online]. Available from: http://www.gcc-legal.org/ MojPortalPublic/BrowseLaws.aspx?country=3 ([Accessed: 28/03/2014])

Qatar National Development Strategy. (2011-2016). Available from: http://www.gsdp. gov.qa/gsdp_vision/docs/NDS_EN.pdf

Qatar's National ICT Plan. (2015). Available from: http://www.ictqatar.qa/en/documents/ document/qatar-s-national-ict-plan-2015-advancing-digital-agenda

California Assembly Bill (AB) 756. (2011). [Online]. California. Available from: http:// www.leginfo.ca.gov/pub/11-12/bill/asm/ab_07010750/ab_746_bill_20110708 chaptered.pdf.[Accessed:25/06/2014]

Qatar Cybercrime Prevention Law No. 14 of. (2014). [Online]. Available from: http:// www.squiresanders.com/files/Publication/1 fa0aa21-69c9-4d8d-915a92cfe1b34a18/Presentation/PublicationAttachment/d0f5d3dd-f6b7-464b-b37393164961a73c/Cybercrime-Law-No-14-of-2014-Unofficial-English-TranslationNovember-2014.pdf ([Accessed: 28/10/2014])

Qatar's ICT landscape. (2009). Available from: http:www.ictqatar.qa/landscape2009/index en.htm ([Accessed 10/05/2014])

Internet World Stats: Usage and Population Statistics (2010). Middle-eastern statistics. Available from: http://www.internetworldstats.com/stats5.htm

Juvonen, J., \& Gross, E. F. (2008). Extending the school grounds? - Bullying experiences in cyberspace. Journal of School Health, 78(9), 496-505.

Kazarian, S. S., \& Anmar, J. (2013). School bullying in the Arab world: A review. The Arab Journal of Psychiatry, 24(1), 37-45.

Kift, S., Campbell, M., \& Butler, D. (2010). Cyberbullying in social networking sites and blogs: Legal issues for young people and schools. Journal of Law, Information and Science, 20, 60-97.

King, A. V. (2010). Constitutionality of cyberbullying laws: Keeping the online playground safe for both teens and free speech. Vanderbilt Law Review, 63(3), 845-884.

Kowalski, R. M., Giumetti, G. W., Schroeder, A. N., \& Lattanner, M. R. (2014). Bullying in the digital age: A critical review and meta-analysis of cyberbullying research among youth. Psychological Bulletin, 140(4), 1073-1137.

Lereya, S. T., Samara, M., \& Wolke, D. (2013a). Parenting behavior and the risk of becoming a victim and a bully/victim: A meta-analysis study. Child Abuse E Neglect, 37(12), 1091-1108.

Lereya, S. T., Winsper, C., Heron, L., Lewis, G., Gunnel, D., Fisher, H. L., \& Wolke, D. (2013b). Being bullied during childhood and the prospective pathways to self-harm in late adolescence. Journal of the American Academy of Child and Adolescent Psychiatry, 52(6), 608-618.

Lidsky, L., \& Garcia, A. P. (2012). How not to criminalize cyberbullying. Available from: http://scholarship.law.ufl.edu/facultypub/173

Microsoft (2012). Worldwide online bullying survey. Available from: http://download. microsoft.com/download/E/8/4/E84BEEAB-7B92-4CF8-B5C7-7CC20D92B4F9/WW\% 200nline\%20Bullying\%20Survey\%20-\%20Executive\%20Summary\%20-\%20Qatar_Final. pdf

Monks, C. P., Smith, P. K., Naylor, P., Barter, C., Ireland, J. L., \& Coyne, I. (2009). Bullying in different contexts: Commonalities, differences and the role of theory. Aggression and Violent Behavior, 14, 146-156.

Nansel, T. R., Overpeck, M., Pilla, R. S., Ruan, W., Simons-Morton, B., \& Scheidt, P. (2001) Bullying behaviors among US youth: Prevalence and association with psychosocial adjustment. Journal of American Medical Association, 16, 2094-2100.

Newey, K. A., \& Magson, N. (2010). A critical review of the current cyber bullying research: Definitional, theoretical and methodological issues. Where do we go from here? Conference Proceedings, Australian Association for Research in Education (AARE) International Education Research Conference, Melbourne.

Olweus, D. (1993). Bullying in schools: Bullies and whipping boys. Washington, DC: Henisphere.

Olweus, D. (1994). Annotation: Bullying at school: Basic facts and effects of a school based intervention program. Journal of Child Psychology and Psychiatry, 35, 1171-1190.

Oman Cybercrime Law (2011). Royal Decree No. 12. Available from: http://www.qcert. org/sites/default/files/public/documents/om-ecrime-issuing_the_cyber_crime_laweng-2011.pdf ([Accessed: 29/08/2016])

Onsor, A., Alameer, A., Almonabih, H., Alqahtani, B., \& Tweem, O. (2012). Bullying amongst students: Characteristics, reasons and consequences. Al Aween: The Social Rehabilitation Centre.

Paul, S., Smith, P. K., \& Blumberg, H. H. (2012). Investigating legal aspects of cyberbullying. Psicothema, 24(4), 640-645.

Pearce, N., Cross, D., Monks, H., Waters, S., \& Falconer, S. (2011). Current evidence of best practice in whole-school bullying intervention and its potential to inform cyberbullying interventions. Australian Journal of Guidance and Counselling, 21, 1-21.
Qatar Population Status (2012). Three years after launching the population policy. Available from: http://www.gsdp.gov.qa/portal/page/portal/ppc/PPC_home/ppc_news/ppc_ files_upload/populations_status_2012_en.pdf

Qatar Statistics Authority (2014). [Online]. Ministry of Development Planning and Statistics. Available from: http://www.qsa.gov.qa/eng/publication/annabs/2014/1_ Population2013.pdf ([Accessed 29/07/2014])

Reijntjes, A., Kamphuis, J. H., Prinzie, P., \& Telch, M. J. (2010). Peer victimization and internalizing problems in children: A meta-analysis of longitudinal studies. Child Abuse $\mathcal{E}$ Neglect, 34, 244-252.

Samara, M., \& Smith, P. (2008). How schools tackle bullying, and the use of whole school policies: Changes over the last decade. Educational Psychology, 28(6), 663-676.

Samara, M., Sherif, M., Perkins, J., Morsi, H., \& El Asam, A. (2014). Understanding the terminology used to describe bullying acts in Qatar. Qatar Foundation Annual Research Conference Proceedings, Vol. 1., SSPP1155. http://dx.doi.org/10.5339/qfarc.2014. SSPP1155.

Scheithauer, H., Smith, P. K., \& Samara, M. (2016). Cultural issues in bullying and cyberbullying among children and adolescents: Methodological approaches for comparative research. International Journal of Developmental Science, 10, 3-8. http://dx. doi.org/10.3233/DEV-16000085.

Shariff, S., \& Hoff, D. (2007). Cyber bullying: Clarifying legal boundaries for school supervision in cyberspace. International Journal of Cyber Criminology, 1(1), 76-118.

Slovak, K., \& Singer, J. B. (2011). School social workers' perceptions of cyberbullying. Children and Schools, 33(1), 5-16.

Smith, P. K., \& Samara, M. (2003). Evaluation of the DfES anti-bullying pack (research brief RBX06-03). London: Department for Education and Skills.

Smith, P. K., Kupferberg, A., Mora-Merchan, J. A., Samara, M., Bosley, S., \& Osborn, R. (2012). A content analysis of school anti-bullying policies: a follow-up after six years. Educational Psychology in Practice, 48, 47-70.

Smith, P. K., Mahdavi, J., Carvalho, M., Fisher, S., Russel, S., \& Tippet, N. (2008a). Cyberbullying: Its nature and impact in secondary school pupils. Journal of Child Psychology and Psychiatry, 49, 376-385.

Smith, P. K., Smith, C., Osborn, R., \& Samara, M. (2008b). A content analysis of school antibullying policies: a follow-up after six years. Educational Psychology in Practice, 24, $1-12$.

Snakenborg, J., Van Acker, R., \& Gable, R. A. (2011). Cyberbullying: Prevention and intervention to protect our children and youth. Preventing School Failure, 55(2), 88-95.

Supreme Education Council (2013, September). Behavioral policy for students in independent schools. Supreme Education Council.

Supreme Education Council (SEC (2011/2012). Annual report on schools and schooling in Qatar. [Online]. Available from: http://www.sec.gov.qa/En/Media/News/Documents/ SchoolsReport2011-2012.pdf ([Accessed: 22/07/2014])

The United Arab Emirates State (UAE). Federal Decree-Law no. 5 of (2012o). On combating cybercrimes no. [Online] Available from: http://ejustice.gov.ae/downloads/ latest_laws/cybercrimes_5_2012_en.pdf ([Accessed: 29/07/2014])

The United Kingdom. Education and Inspections Act (2006). [Online]. Available from: http://www.legislation.gov.uk/ukpga/2006/40/contents ([Accessed: 04/05/2014])

The United Kingdom. School Standards and Framework Act (1998). [online] Section 61(4) (B). London: HMSO Available from: http://www.legislation.gov.uk/ ukpga/1998/31/contents ([Accessed: 06/06/2014])

Tokunaga, R. S. (2010). Following you home from school: A critical review and synthesis of research on cyberbullying victimization. Computers in Human Behavior, 26, 277-287.

U.S. Department of Education (2011). Analysis of state bullying laws and policies. Washington, DC: U.S. Government Printing Office.

Vandebosch, H., Beirens, L., D'Haese, W., Wegge, D., \& Pabian, S. (2012). Police actions with regard to cyberbullying: The Belgian case. Psicothema, 24(4), 646-652.

Williford, A., Elledge, L. C., Boulton, A. J., DePaolis, K. J., Little, T. D., \& Salmivalli, C. (2013). Effects of the KiVa Antibullying program on cyberbullying and cybervictimization frequency among Finnish youth. Journal of Clinical Child E Adolescent Psychology, 42(6), 820-833. http://dx.doi.org/10.1080/15374416.2013.787623.

Wolke, D., \& Samara, M. M. (2004). Bullied by siblings: Association with peer victimisation and behaviour problems in Israeli lower secondary school children. Journal of Child Psychology and Psychiatry, 45(5), 1015-1029.

Wolke, D., Schreier, A., Zanarini, M. C., \& Winsper, C. (2012). Bullied by peers in childhood and borderline personality symptoms at 11 years of age: A prospective study. Journal of Child Psychology and Psychiatry, 53(2), 846-855.

Wolke, D., Woods, S., Bloomfield, L., \& Karstadt, L. (2000). The association between direct and relational bullying and behaviour problems among primary school children. Journal of Child Psychology and Psychiatry, 41(8), 989-1002.

Ybarra, M. L., \& Mitchell, K. J. (2004). Online aggressor/targets, aggressors, and targets: A comparison of associated youth characteristics. Journal of Child Psychology and Psychiatry, 45(7), 1308-1316. 